HISTÓRIA DA FILOSOFIA

\title{
Condición, naturaleza humana y el origen de la sociedad civil en la filosofía vitoriana
}

\author{
Human condition, human nature, and the origin \\ of civil society in Francisco de Vitoria's philosophy
}

* Diego Alfredo Perez Rivas

\begin{abstract}
Resumen: En la filosofía de Francisco de Vitoria la creación de la sociedad civil es causada por la vulnerabilidad de la condición humana, así como por el posterior desarrollo de las facultades intelectuales. Vitoria planteó que el poder civil residía fundamentalmente en la república, no siendo transferido mediante gracia divina a ninguna persona en particular. En esta visión, la discusión sobre el origen de la sociedad civil es desarrollada mediante argumentos filosóficos y excluyendo los argumentos teológicos como la gracia divina. Con estas ideas creó un primer puente que conecta su visión con las teorías modernas de la soberanía popular. En el artículo se propone la revisión de las ideas de Vitoria considerando tres dicotomías: la gracia y la naturaleza humana, el lógos y la sociabilidad, la racionalidad y la libertad.
\end{abstract}

Palabras clave: Francisco de Vitoria. Sociedad civil. Naturaleza humana. Condición humana. Derechos.

\begin{abstract}
According to Francisco de Vitoria's philosophy the vulnerability of the human condition and the development of intellectual faculties are the causes leading to the creation of civil society. Vitoria asserts that civil power lies within the republic, as it is not bestowed, via divine grace, to any specific person. On this premise, Vitoria develops the discourse around the origin of civil society through a philosophical investigation, rejecting theological explanations such as the divine grace. Thanks to this approach, Vitoria forges an early
\end{abstract}

* Pós-Doutorado na Universidade de Turim, Itália, Departamento de Filosofia. Membro do Sistema Nacional de Investigadores Conacyt-Mexico. Pesquisa financiada pelo Conacyt, por meio de bolsas de pós-doutorado para pesquisadores internacionais. 
connection with modern theories about popular sovereignty. In this paper, Vitoria's thesis is discussed through the analysis of three dichotomies: divine grace and human nature, language and sociability, rational thought and freedom.

Keywords: Francisco de Vitoria. Civil society. Human nature. Human condition. Rights.

\section{Introducción}

T as discusiones sobre el origen de la sociedad civil, sobre la ـundamentación del origen y las funciones del poder público, pueden considerarse ejes centrales en la filosofía política. De hecho, una gran inflexión en estas concepciones ha caracterizado a la filosofía moderna. En el medioevo fue predominante tanto una concepción naturalista, como una concepción vertical del origen de la sociedad civil y de la fundamentación del poder político. Mientras tanto, en la edad moderna ha predominado una concepción convencionalista y horizontal. La filosofía política de Francisco de Vitoria se ubicó, histórica y teóricamente, en el centro de esta ruptura. El presente ensayo tiene como objetivo principal contribuir al conocimiento y difusión de su obra.

En el presente artículo mostraré cuáles fueron los principales rasgos de la naturaleza y la condición humana en su pensamiento. Sostendré que en su fundamentación del origen de la sociedad y el poder político existe un primer avance hacia la noción de legitimidad popular. La disertación la dividiré en tres fases. Primeramente, explicando la solución vitoriana a la posible influencia del estado de gracia en la naturaleza humana. En segundo lugar, resaltando el lugar asignado al lógos en el proceso de sociabilidad. Finalmente, expondré la íntima relación entre racionalidad y libertad. Mediante estas fases se podrá observar que la formulación vitoriana sobre el origen de la sociedad civil y el poder público se fundamenta en su peculiar concepción de la naturaleza y la condición humana.

\section{Estado de gracia y naturaleza humana}

El tema de la naturaleza humana y su relación con el estado de gracia es un tópico clave en el pensamiento de Vitoria, como lo fue también en las discusiones teológicas medievales. En términos generales fue comúnmente aceptada la tesis que predicaba que el ser humano perdería la parte más importante de sus facultades intelectuales, morales y 
jurídicas por la carencia de la gracia. Vitoria defendió una tesis opuesta, según la cual el estado de gracia no es determinante en la posesión y en el ejercicio de dichas facultades.

En la Suma teológica, Aquino afirmó la existencia de tres posibles acepciones de la gracia: como amor, como don y como reconocimiento de un beneficio gratuito ${ }^{1}$. Según esto, la gracia era considerada un don gratuito concedido por amor divino. Su manifestación, sin embargo, podría expresarse de dos modos diferentes. En primer lugar, como el amor común según el cual Dios ama todas las cosas creadas. En segundo lugar, como el amor especial que eleva al ser humano sobre su condición natural, haciéndolo participe del bien divino. La gracia fue concebida, así, como una donación sobrenatural que perfeccionaría la naturaleza humana. En el primer caso, como el amor universal del creador hacia todos los seres creados; en el segundo, como un tipo de amor especial del que solamente participan algunos seres humanos.

En la tradición medieval, la idea del pecado original fue determinante para la formación de las concepciones sobre la naturaleza y la condición humana. Se distinguía, por una parte, el estado de integridad en el que presuntamente estuvo el ser humano en el paraíso antes del pecado original. Por otra, el estado de caída o corrupción, entendido como consecuencia del pecado original ${ }^{2}$. Mientras que en el estado de integridad el ser humano podía considerarse un ser con la capacidad de querer y hacer el bien por sí mismo; en el estado de corrupción, el ser humano estaría hipotéticamente por debajo de su propia naturaleza ${ }^{3}$. La gracia divina sería, en estas circunstancias, el don divino que enmendaría la naturaleza corrompida por el pecado original y la caída.

$\mathrm{El}$ análisis que presentaré sobre la gracia considera tres momentos cruciales en la formulación vitoriana. Primeramente, será expuesta la tesis que destaca la distinción del poder eclesiástico y civil considerando el estado de gracia. En segundo lugar, su aproximamiento al tomismo determinando que el estado de gracia no altera sustancialmente la naturaleza humana, sino que la perfecciona en el contexto de lo sobrenatural. Por último, se expondrá la fundamentación al derecho

TOMÁS DE AQUINO, Suma teológica, I-II q. 110, a. 1.

2 Cf. CRUZ, J., Fragilidad humana y ley natural. Cuestiones disputadas en el Siglo de Oro, p. 19: "Bajo la carga de estos problemas la patrística empezó a distinguir un doble derecho natural: uno primario, correspondiente al estado de naturaleza íntegra; otro secundario, propio del estado de naturaleza caída y redimida. Se trataba entonces de estados históricos sucesivos. Más adelante, en la primera Escolástica se identificó al derecho natural primario con los preceptos de la primera tabla del Decálogo - preceptos absolutamente inmutables, por hacer referencia al mismo Dios -; en cambio, el derecho natural secundario correspondería a los preceptos de la segunda tabla, los cuales hacían referencia al orden creado".

3 TOMÁS DE AQUINO, Suma teológica, I-II, q. 109, a. 2. 
de propiedad, resaltando el hecho de que se considera a la naturaleza humana, y no a la gracia divina, como su peculiar y radical fundamento.

En sus comentarios a la II-II, Vitoria discutió la posibilidad de fundamentar el ius iudicandi ("derecho de juzgar") en el estado de gracia. En oposición a esta idea, consideró que "La gracia no es el título para juzgar, como lo es para recibir la eucaristía, sino que el título para juzgar es la autoridad"4. Para Vitoria el estado de gracia podría considerarse como conditio sine qua non en la administración de los sacramentos religiosos. Sin embargo, la consideró irrelevante en la administración de los asuntos civiles, porque no tienen como misión ni la redención ni el favor divino. Con esta tesis planteó que todo lo que está asociado con el origen y la administración de la sociedad civil debería considerarse separadamente a la cuestión del estado de gracia.

En el momento en el que se construyó la doctrina del estado de gracia como fundamento del ius iudicandi, la Iglesia católica se enfrentaba a un gran cisma. En ese contexto, predominó el cuestionamiento sobre los posibles fundamentos de la autoridad eclesiástica y civil ${ }^{5}$. Reformistas como Wyclif y Hus plantearon que el derecho de juzgar dependía de la gracia divina. En el lado de la contrarreforma, Vitoria defendió la tesis según la cual los seres humanos no pierden la capacidad de juzgar, como tampoco pierden la dignidad humana, por ningún pecado ni por la carencia de la gracia. Expuso, opuestamente, que "la gracia no corrompe la naturaleza: Dios dispone todas las cosas con suavidad"6. Agregando que "en los infieles no está corrompida la naturaleza"7.

4 FRANCISCO DE VITORIA, Comentarios a la II-II, q. 60, a. II, 3.

5 Cf. FOUCAULT, M. Sicurezza, territorio, popolazione. Corso al Collège de France (1977-1978), p. 157-158: "El fondo teórico consiste en la refutación de la autoridad del pastor y de la justificación teológica y eclesiológica que no habían estado propuestas con anterioridad. En particular, la comunidad, al menos la más violenta y virulenta, más alejada de la Iglesia, parte del principio de que la Iglesia misma y, en particular, su organismo central y principal, Roma, es la nueva Babilonia y representa al anticristo. Este es un tema moral y apocalíptico. En el grupo más culto, en una forma poco sutil, esta incesante actividad, siempre renovada, de creación de la comunidad sí está constituida sobre la base de ciertos problemas doctrinales importantes. En primer lugar se observaba el problema del pastor en condición de pecado: ¿el pastor debe el privilegio de su poder y de su autoridad a un signo recibido una vez para siempre y entonces indeleble? ¿En otras palabras, el hecho de ser cura y estar ordenado, lo hace poseedor de un poder que en definitiva no puede serle revocado, a menos que sea suspendido por una autoridad superior? ¿El poder del pastor es independiente del valor moral de quien lo ejercita, de su mundo interior, de su manera de vivir, de su conducta? El problema que afecta toda la economía de los méritos y los deméritos en los que vivió por última vez. Algunos personajes han respondido a tales cuestiones en términos estrictamente teóricos teológicos y eclesiológicos; pienso sobre todo en Wyclif y en Jan Hus. El principio postulado por Wyclif decía: No existe dominio civil, ni episcopal si se está en pecado mortal... En otros términos, el solo hecho de devenir en un estado de pecado mortal suspende todos los poderes que un pastor puede ejercitar sobre los fieles".

6 FRANCISCO DE VITORIA, Comentarios a la II-II, q. 173, a. 2, VI, 270.

7 Ibid., q. 10, a. 4, I, 169, 1. 
Para Vitoria, la ausencia de la gracia no era un impedimento para la aparición de las facultades que componen la naturaleza humana. De modo opuesto, la gracia se referiría exclusivamente al problema sobrenatural de la salvación, sin incidir en la conformación de la naturaleza humana. Esta posición fue fundamental en su obra, pues la utilizó como base para desarrollar la defensa de los derechos de los indígenas americanos, a los que nunca consideró impedidos en su naturaleza y dignidad por el argumento de la infidelidad o del pecado. Sobre este tema se ha escrito mucho por lo que aquí no me ocuparé en especificarlo con precisión.

En 1532, desarrolló la tesis según la cual el poder secular reside en los miembros que componen la República, teniendo como su fundamento la naturaleza y la condición humana. Mientras que, por otro lado, se posicionó en favor de la tesis que consideraba que la potestad eclesiástica se fundaba en una donación divina teniendo como exclusiva finalidad la salvación. Desde su punto de vista, la sociedad civil estaría constituida para resolver problemas humanos exclusivamente terrenales.

La causa de que Vitoria haya sido capaz de plantear ideas filosóficas actuales como el reconocimiento universal de la humanidad de los indígenas americanos, reside en que fue capaz de liberar la discusión en torno al origen de la sociedad civil del tema de la gracia divina. En su teología, la gracia tiene tanto un fundamento como objetivos exclusivamente religiosos: la gratuidad divina y la redención. Planteó que la ausencia de gracia no corrompe la naturaleza humana, ni afecta los rasgos sustanciales de dicha naturaleza. Finalmente, estableció que la gracia no es el fundamento del derecho de propiedad ni del derecho de juzgar.

Para demostrar de qué manera podía configurarse una concepción de la sociedad civil compatible con las exigencias de la inclusión y el universalismo, expuso que el fundamento del derecho a la propiedad es la naturaleza humana. Con tal postura dotó de elementos a una visión universalista de la sociedad civil donde era necesario proteger los derechos de los seres humanos independientemente de sus creencias religiosas. En este sentido, Vitoria explica en De indis que:

Algunos hubo que defendían que el título de dominio es la gracia, y, por lo tanto, que ningún dominio tienen sobre las cosas los pecadores, al menos aquellos que actualmente estén en pecado mortal. Error fue éste de los pobres de Lyon o Valdenses, y después de Juan Wyclif, uno de cuyos errores, condenado en el Concilio de Constanza, dice: Nadie es señor civil mientras esté en pecado mortal ${ }^{8}$.

8 FRANCISCO DE VITORIA, "De indis recenter inventis relectio prior", in: FRANCISCO DE VITORIA, Relecciones teológicas, p. 651-652. 
Vitoria sostuvo que la gracia divina no altera el derecho de propiedad ni la potestad civil. Defendió también la tesis según la cual todo tipo de dominio se funda exclusivamente en los rasgos sustanciales de la naturaleza humana. Esta concepción contiene una doble fundamentación. Por una parte, un fundamento onto-teológico según el cual el ser humano está hecho a imagen y semejanza de Dios, porque es verbo y lógos. Por otra parte, un fundamento ontológico secular según el cual el ser humano posee facultades racionales, intelectuales y volitivas, en concordancia con la concepción aristotélica. En su visión, la naturaleza humana permitiría el disfrute de dos capacidades o potencias sustanciales. Por un lado, la facultad racional para entender los principios de las cosas eternas. Por otro, la facultad volitiva para decidir sobre el propio obrar y destino. Vitoria consideró que con el pecado o con la ausencia de la gracia no se pierden jamás estas capacidades.

\section{Origen de la sociedad civil}

En la Relección sobre la potestad civil, Vitoria manifestó que la investigación sobre el origen de la sociedad civil debería configurarse siguiendo un criterio teleológico. Influido por las tesis aristotélicas, explica que "tenemos conocida una cosa cuando conocemos sus causas [...]. No sólo en las entidades naturales y tangibles, sino también en todas las cosas humanas, la necesidad ha de ser ponderada por el fin, que es causa primera y principal de todas"

La tesis vitoriana sobre el origen de la potestad civil se contrapone explícitamente a la teoría materialista-atomista defendida por filósofos antiguos como Epicuro y Lucrecio. De hecho, en la introducción a su texto criticó dichas teorías, considerándolas absurdas por basarse en principios casualistas que apelan al azar y a la no-finalidad. La crítica vitoriana a dichas tesis consiste en afirmar que para aquellas: "todo es casual y ocurre merced al gratuito y múltiple concurso de los átomos que pululan por el vacío infinito" ${ }^{10}$. Para Vitoria, por el contrario, existirían evidencias claras de la participación de la inteligencia divina en la creación y en el gobierno del universo. Por tanto, su postura, radicalmente opuesta a la de los materialistas, sostiene que "todo absolutamente existe por algún fin, en el que hay que buscar su razón de ser y su necesidad"11.

La teoría política de Vitoria posee también una fuerte inspiración teológica que se manifiesta en su búsqueda incesante de la causa

9 FRANCISCO DE VITORIA, "De potestate civili”, in: FRANCISCO DE VITORIA, Relecciones teológicas, p. 151-152.

10 Ibid., p. 153.

11 Ibid., p. 153-154. 
eficiente. En su pensamiento, tanto la naturaleza como la condición humana son concebidas como obras divinas. Ni el ambiente en el que se desenvuelve el ser humano ni sus facultades e inclinaciones esenciales son pensadas como algo creado artificialmente, sino como productos directos de la acción y la voluntad de Dios.

La causa primera o eficiente de la potestad civil la atribuye, por lo mismo, a la entidad suprema. En tal sentido, explicaba que "todo poder público o privado [potestate publica et privata] por el cual se administra la república secular, no sólo es justo y legítimo, sino que tiene a Dios por autor de tal suerte que ni por el consentimiento de todos se puede suprimir" ${ }^{12}$. La postura de Vitoria respecto a la causa eficiente del poder civil lo liga estrechamente con el pensamiento medieval. Sin embargo, en el marco general de su teoría sobre el origen de la sociedad y de la potestad, la divinidad solamente es considerada como una causa entre otras.

En la filosofía vitoriana, la característica más importante de la condición humana es la fragilidad. Los seres humanos son concebidos como animales biológicamente débiles que solamente pueden sobrevivir por el uso de su inteligencia y por su capacidad de socializar. La solución a la indigencia de la condición humana constituiría la causa final de la sociedad civil. En esa serie de ideas, la sociedad civil es comprendida como algo que se forma por la naturaleza y la necesidad humanas y no por un acto convencional al que se puede renunciar voluntariamente. En sus palabras:

Sólo al hombre, concediéndole la razón y la virtud, dejo frágil, débil, pobre, enfermo, destituido de todos los auxilios, indigente, desnudo e implume, como arrojado de un naufragio; en cuya vida esparció las miserias, puesto que desde el momento de su nacimiento nada más puede que llorar la condición de su fragilidad y recordarla con llantos, según aquello de Job: repleto de muchas miserias, y al que sólo resta dejar pasar los males, como dijo el poeta ${ }^{13}$.

Para Vitoria, la condición humana se caracteriza por la fragilidad y la debilidad. Su postura evoca el mito protagórico en el que la sociedad política es comprendida como la solución humana para resolver el problema de la indigencia. De dicha vulnerabilidad natural con la que el ser humano se enfrenta desde el nacimiento, surgiría la necesidad, primero biológica y después espiritual, de desarrollar la vida en sociedad. $\mathrm{Al}$ igual que en la filosofía aristotélica, los inconvenientes de la vida

12 Ibid., p. 151.

13 Ibid., p. 154-155. 
natural son resueltos en el momento de la organización familiar y en la aldea. Sin embargo, es en la pólis donde se desarrollan plenamente las facultades de su naturaleza. Respecto a esto, explicó:

Para subvenir a esta necesidad fue necesario que los hombres no anduviesen vagos, errantes y asustados, a manera de fieras, en las selvas, sino que viviesen en sociedad y se ayudasen mutuamente. iAy del solo!, dice el Sabio, porque si se cayere, no encontrará quien le levante; pero, si fueren muchos, mutuamente se ayudarán ${ }^{14}$.

La indigencia, vulnerabilidad y desprotección natural del ser humano son compensadas, en la filosofía vitoriana, por el desarrollo de la sociabilidad. Es importante aclarar que uno de los aspectos más innovadores del pensamiento vitoriano es que en su filosofía el momento de la sociabilidad no se caracteriza simplemente por la búsqueda de la supervivencia. Contrariamente, la sociabilidad es comprendida como un proceso para alcanzar la civilidad, un estado social en el que se crean responsabilidades para todos los individuos y en el que se combate el estado salvaje en el que predominaba la fragilidad. En otras palabras, pertenecer a la sociedad civil significaría encontrar amparo en los otros, a condición de ofrecer el mismo amparo a los demás. En opinión de Juan Cruz:

Para explicar la apertura [Offenheit] consustancial del hombre a los demás - apertura que es la raíz de sus múltiples relaciones en comunidad y en sociedad -, Vitoria comienza utilizando la argumentación que ya Platón recogió en su Protágoras [...] el hombre es inicialmente un ser deficitario [Mangelwesen], y por su indefensión tiene necesidad de la comunidad para satisfacer sus necesidades [...] pero la indigencia o la falta no es la razón última en que se fundamenta la vida de la comunidad. Es la natural perfección de la palabra, radicada en la inteligencia, la que culmina la intercomunicación humana ${ }^{15}$.

Respecto a la naturaleza social y política del ser humano, Vitoria se apegó fielmente a la concepción aristotélica. El momento en el que es más evidente la defensa del aristotelismo es cuando contradice las teorías convencionalistas, según las cuales la sociedad sería el mero producto de convenciones sociales y la materialización de los intereses egoístas de sus miembros. De modo opuesto, Vitoria concibió la sociabilidad como una necesidad y no como una elección. Respecto a esto, indicó:

La fuente y origen de las ciudades y de las repúblicas no fue una invención de los hombres, ni se ha de considerar como algo artificial,

14 Ibid., p. 155.

15 CRUZ, J., op. cit., p. 157-158. 
sino como algo que procede de la naturaleza misma, que para defensa y conservación sugirió este modo de vivir social a los mortales. De ese mismo capítulo se infiere prontamente que el mismo fin tiene y la misma necesidad que las ciudades los poderes públicos. Porque si para guarda de los mortales son necesarias las congregaciones y asociaciones de los hombres, ninguna sociedad puede persistir sin alguna fuerza y potestad que gobierne y provea. La misma es, pues, la utilidad y el uso del poder público que el de la comunidad y sociedad ${ }^{16}$.

La concepción de la sociabilidad natural mencionada por Vitoria se inspira en Aristóteles, quien al hablar de physis en los textos metafísicos explicaba que por naturaleza se entiende la sustancia [ousía] de los entes naturales ${ }^{17}$. Es decir, los hombres son considerados seres sociales por naturaleza porque solamente en la sociabilidad puede desarrollarse la verdadera esencia del ser humano. Contrariamente, cuando el ser humano vive aislado no desarrolla sus facultades esenciales, además de encontrarse inmerso en una condición de absoluta vulnerabilidad y fragilidad. Por esa razón, Vitoria consideró que la necesidad natural obliga a los individuos a desarrollar sus capacidades esenciales en la vida social y civil.

En la teoría vitoriana la forma adoptada por la sociedad civil puede considerarse como algo creado artificial y convencionalmente. No obstante, la existencia de la sociedad y el poder público serían inexorables, porque solamente mediante dichos instrumentos el hombre podría abandonar su indigencia natural, así como desarrollar sus capacidades intelectuales y espirituales. Por la misma razón, consideró que la causa final de la sociedad civil consistía en enfrentar la condición originaria de vulnerabilidad, si bien es cierto, aceptando que dicha solución puede manifestarse de diversos modos según su causa material. La solución de la filosofía vitoriana al problema del origen de la sociedad civil y del poder público denota una clara comprensión de lo que sería el fundamento de la filosofía política moderna, es decir, la idea de que la forma adoptada por el poder político era algo que podía resolverse mediante el consenso, teniendo siempre como condición necesaria el respeto de los derechos fundamentales.

En el pensamiento vitoriano está presente la idea de que mediante la congregación de los individuos en una ciudad es posible encontrar la cura al estado de indigencia. Pero, para que la sociedad pueda tener un orden estable resulta necesaria la erección de un poder público encargado de administrar los asuntos públicos. Por lo mismo, dicho poder

16 FRANCISCO DE VITORIA, De potestate civili, p. 157.

17 ARISTÓTELES, Metafísica, v. 4, $1014 b$. 
tendría la misión de gestionar la vida común, procurando que todos los individuos encuentren cura a su estado de indigencia natural mediante el establecimiento de un cierto estado de civilidad. Respecto a esto, aclara:

Si todos fueran iguales y ninguno estuviera sujeto al poder, tendiendo cada uno por su privado parecer a cosas diversas, necesariamente se desharían los negocios públicos; y la ciudad se disolvería si no hubiera alguno que proveyese, cuidase de la comunidad y mirase por los intereses de todos. Todo reino dividido entre sí, quedará desolado; y donde no hay gobernante, se disipará el pueblo, como dice el sabio $^{18}$.

El pensamiento de Vitoria se apega a la formulación aristotélica, donde la ciudad es diferenciada de otras organizaciones humanas por la autosuficiencia que se construye en su seno. A diferencia de la familia o del clan, que son incapaces de producir todos los bienes necesarios para la vida, la ciudad es considerada como la organización humana que asegura la protección de todos sus miembros. De tal modo, el primer derecho que tendrían los individuos que forman parte de una ciudad sería el aseguramiento de su protección física. En este sentido, Vitoria aclaró: "Aunque los miembros de la familia se ayuden mutuamente, una familia no puede bastarse a sí, sobre todo tratándose de repeler la fuerza y la injuria"19.

La finalidad de la sociedad civil consistiría en compartir las cargas que implica la salida del estado de indigencia e inseguridad. El poder político es concebido, entonces, como el centro que organizaría los asuntos públicos para asegurar el éxito de dicha empresa. La necesidad del poder político consistiría en mantener unida la sociedad, pero sin vulnerar los derechos naturales de sus miembros.

Vitoria propuso cuatro causas de la sociedad civil y el poder político, calcadas del modelo aristotélico. La causa eficiente estaría contenida en el derecho natural, siendo Dios el autor de dicho derecho considerado como irrenunciable y no contenido necesariamente en el derecho positivo ${ }^{20}$. La causa final sería la utilidad humana que serviría para salvar la condición indigente del ser humano ${ }^{21}$. La causa material del poder público residiría por derecho natural y divino en la propia república a la que le compete gobernarse, administrar y dirigir al bien común todos sus poderes ${ }^{22}$.

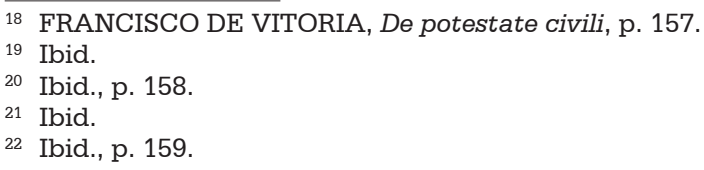


Finalmente, lo que concibe como causa formal es "la facultad, autoridad o derecho de gobernar la república civil"23.

En la filosofía vitoriana la causa eficiente de la sociedad civil y del poder político es Dios, siguiendo la tradicional fórmula medieval que considera la legitimidad religiosa como el principal fundamento de la autoridad. Pero, por otra parte, aparece expresada por primera vez una causa material que encuentra su razón de ser en la voluntad de los miembros de la propia república. Su propuesta, por tanto, consistió en afirmar que la soberanía, o causa material, recae directamente en los ciudadanos y no en las autoridades. Su teoría política, en este punto, representa un punto de inflexión entre el mundo medieval y el mundo moderno. Siguiendo sus ideas, Dios habría impreso en los seres humanos su condición vulnerable y su naturaleza social. Al mismo tiempo, desde el punto de vista material, habría empoderado a la sociedad civil para decidir sobre su propio destino. El único precepto irrenunciable de la sociedad sería el siguiente: "Si el hombre no puede renunciar al derecho de defenderse y de usar de los miembros propios para su comodidad, tampoco puede renunciar a la potestad que le compete por derecho natural y divino" 24 .

En la filosofía vitoriana, el ser humano no puede dimitir de su obligación de salir de la condición de vulnerabilidad mediante el desarrollo de las facultades de la naturaleza humana, entre ellas, la sociabilidad. El derecho natural establecería en el pueblo o la república una especie de derecho-obligación, según el cual el ser humano, por su propia naturaleza, tiene la obligación y el derecho de formar parte de una sociedad civil. Los objetivos de la sociedad civil y del poder político estarían, pues, encaminados a resolver la indigencia y la desprotección natural, creando un ambiente de civilidad compartida.

La forma en la que Vitoria, y posteriormente otros exponentes de la Escuela de Salamanca, llevaron a cabo su aportación a la filosofía moderna fue explicando que la juridicidad sólo es posible desde el principio de la inclusión política y jurídica. Es decir, el poder político y la sociedad civil solamente tienen sentido cuando se fundan en el reconocimiento universal de la personalidad jurídica de sus miembros, pues solamente dicho reconocimiento permite vincular las acciones de todos los sujetos a las mismas normas. El principio jurídico moderno del Estado de Derecho, o del imperio de la ley, consistiría precisamente en que todos los individuos se sujetan al mismo sistema normativo como súbditos. La concepción vitoriana sobre el origen de la sociedad civil 
como producto de la naturaleza y la condición humanas fue fundamental para dar vida a esas ideas.

\section{Lógos y politicidad}

En el pensamiento de Vitoria, el fundamento de la sociedad civil se encuentra en la vulnerabilidad de la condición humana y en la naturaleza social del ser humano. La finalidad de la sociedad consistiría, primeramente, en salvaguardar la producción de los bienes necesarios para la vida; en segundo, en proveer un orden estable para que los individuos puedan desarrollar sus facultades naturales en un ambiente de civilidad. Todas estas ideas apelan a las facultades más representativas de la naturaleza humana: la posesión del lenguaje y el desarrollo de la politicidad.

La filosofía política de Aristóteles sostenía que el hombre es un animal político porque es un ser dotado de razón y lenguaje. Es decir, no se considera como animal político por su condición de vulnerabilidad, por necesitar desde su nacimiento una familia u hogar para su protección. De hecho, en el imaginario griego, el oikos u hogar es la forma de organización privada que se opone por definición a la pólis. La familia constituye lo privado, de la misma manera que la vida ciudadana constituye lo público. Por la misma razón, del hecho de que el ser humano necesite por naturaleza pertenecer a una familia o a una tribu para salvar su indigencia no se puede deducir su politicidad. Aristóteles explicaba que existen muchos animales que cuidan de sus crías y se reúnen instintivamente para brindarse protección. En este sentido, partiendo de una primitiva observación biológica aclaró que muchas especies animales son gregarias por naturaleza, pues permanecen en sociedad para protegerse o brindarse seguridad. A este tipo de seres recurre también para diferenciar al ser humano, identificándolo como poseedor exclusivo del lógos.

El ser humano es un animal político y social en un sentido excelente porque puede comunicarse. Lo político, así, se distingue de lo familiar porque en la familia hay una relación asimétrica en la que el padre se erige como déspota, mientras los demás miembros del oikos están bajo su mando y protección. En el imaginario aristotélico, el régimen familiar está conformado de tal modo que el único que puede hablar, el poseedor del lógos, del razonamiento y la verdad es el pater familias. En cambio, en la pólis, en la vida política-pública, todos los ciudadanos serían iguales, teniendo en común el espacio de verdad público que es la justicia civil.

Aristóteles pensaba además que el ser humano adquiere tres formas peculiares de percibir la realidad gracias al lógos. El conocimiento de esas nociones y la relación que se tiende entre ellas en el espacio de 
verdad común es lo que separa al ser humano del resto de los animales gregarios. Mientras los animales solamente tienen phoné, emitiendo sonidos inarticulados para expresar placer y dolor; los seres humanos poseen el lógos para expresar nociones abstractas como "lo conveniente y lo dañoso", "lo justo y lo injusto", "lo bueno y lo malo". Mediante la utilidad, se desarrollan conocimientos prácticos para salvar la indigencia. Mediante lo justo, se crea un horizonte deóntico y ético que sirve para regir las relaciones sociales. Finalmente, mediante lo bueno el hombre es capaz de interactuar en un horizonte axiológico y hasta religioso. En otras palabras, el lógos es el elemento clave para distinguir al ser humano libre y ciudadano que participa de las cargas y beneficios de la politicidad. Vitoria tenía una profunda comprensión de estas ideas al exponer que:

El hombre sobrepasa a los animales por la razón, por la sabiduría y por la palabra [ratione, sapientia atque sermone], así a este eterno, inmortal y sabio animal muchas cosas le fueron negadas por la Providencia que fueron atribuidas a los restantes animales. Primeramente, mirando por el bien conjunto y la defensa de los animales, ya desde el principio a todos ellos dotó la madre Naturaleza de ser cubiertas y vestidos con los cuales pudiesen fácilmente sufrir la fuerza de las lluvias y de los fríos ${ }^{25}$.

En la filosofía vitoriana, la naturaleza humana se distingue de la mera naturaleza animal por la aparición del lógos. Vitoria pensaba que a pesar de su desprotección natural, de su indigencia y vulnerabilidad biológica, el ser humano es capaz de buscar protección y seguridad en la sociedad civil. Es decir, es el lógos lo que distingue a las sociedades humanas de las animales, pues por aquella facultad podemos comunicarnos y formar grupos más complejos que la familia o la tribu. La vulnerabilidad sería la causa natural que impulsaría al ser humano a buscar refugio en la compañía de otros, pero el lógos sería lo que posibilitaría la mutua comprensión y ayuda en un ambiente de civilidad. En otras palabras: el lógos es considerado el instrumento inter-subjetivo que permite al ser humano vivir en una dimensión de constante apertura frente a las necesidades y los derechos de los otros. O como dice Vitoria: "la palabra es nuncio del entendimiento, dada a los hombres para elevarse por encima de los animales"26.

Siguiendo el pensamiento aristotélico, Vitoria planteó que el hombre es por naturaleza un ser social y civil merced al lógos, siendo la palabra el instrumento de la actividad política por excelencia. La sociedad civil es concebida como el espacio público que posibilitaría el intercambio

25 Ibid., p. 154.

26 Ibid., p. 155. 
de ideas entre sujetos que respetan, mutuamente, sus derechos. Por lo mismo, el poder político es comprendido como la institución encargada de fomentar la justicia y la amistad entre los seres humanos. Así, mediante la justicia, el ser humano practicaría una virtud civil de mutua comprensión y de mutua ayuda. En este sentido, explica: "La justicia consiste en una relación a otro y no en una relación a sí mismo; por el contrario, las demás virtudes consisten en una relación a sí mismo y no a otro [...]. Por la justicia nada adquirimos para nosotros, sino que por ella damos a otros lo que es suyo"27.

Para Vitoria, lo que distingue a la justicia de otras virtudes es su carácter público. La justicia es pensada, pues, como el valor supremo de la sociedad civil. La sociabilidad sacaría de la indigencia al ser humano, mientras la justicia restablecería toda su dignidad mediante la protección de los derechos naturales del ser humano. Por lo mismo, explica:

En el objeto de la justicia, es decir, en lo justo, no hay que tener en cuenta la condición del agente, es decir, si es rico o pobre el que compra, con tal de que dé lo equivalente [...]. La justicia nunca considera si se trata de un rey o de un hombre poderoso, o si es bueno o pobre el que debe algo, sino que considera lo que es justo, es decir, que devuelva al otro lo que le debe ${ }^{28}$.

La justicia, planteada así, se fundaría en la igualdad ante la ley, contrariamente a la concepción del derecho medieval en la que la administración de la justicia consideraba y justificaba algunos privilegios estamentales. La tesis de Vitoria es moderna, porque planteó que el derecho (ius) no puede derivarse de la justitia como lo proponía Ulpiano. En cambio, pensaba al derecho (ius) como objeto y la justitia como producto de ese objeto. De ese modo, separó la concepción moral de lo bueno de la concepción jurídica de lo justo, aduciendo que para que algo sea conforme a derecho no basta que sea bueno, sino más bien que sea debido. En sus propias palabras:

Hablando con propiedad, no todo lo bueno se dice justo, ni lo bueno que está en relación a otro: esto no es suficiente, sino que se requiere que eso bueno recaiga de algún modo bajo la necesidad de lo debido, es decir, que sea debido ${ }^{29}$.

No corresponde a la justicia considerar si soy rico o pobre, sano o enfermo, sino solamente si debo algo a otro o $\mathrm{no}^{30}$.

\footnotetext{
27 FRANCISCO DE VITORIA, Suma teológica, II-II, q. 57, a. 1, 3.

28 Ibid., a. 1, 4.

29 Ibid., a. 1, 8.

30 Ibid., a. 1, 10.
} 
Vitoria parece vislumbrar, en algunos de sus aspectos más importantes, el principio moderno de la igualdad ante la ley. Aunque su visión sea claramente embrionaria, en su filosofía está presente la idea que sostiene que los seres humanos son iguales por naturaleza, esto es, por su inclinación social y por su facultad de raciocinio. En esta concepción, el individuo es pensado como un animal que por ser parlante y racional tendría una serie de derechos naturales que deberían ser respetados tanto en las relaciones inter-subjetivas, como en las relaciones entre individuos y Estados.

En el pensamiento de Vitoria se puede encontrar también una clara diferenciación entre lo justo por naturaleza (derecho natural) y lo justo por pacto (derecho positivo o humano). En su filosofía está presente la afirmación del derecho objetivo como derecho natural, así como la afirmación del derecho positivo mediante pactos públicos. Vitoria jamás negó la existencia del derecho positivo ni tampoco lo consideró un instrumento estéril. Opuestamente, creyó que su afirmación era necesaria para el establecimiento de la justicia en la sociedad de naciones. En dicho sentido indica: "Justo es lo que es igual por la determinación de una ley o por un pacto privado, y no por su propia naturaleza [...] no es algo determinado por su propia naturaleza sino por un pacto. Lo justo así entendido unas veces consta por un pacto humano privado, otras por un pacto público, y esto se llama ley" ${ }^{31}$.

La teoría vitoriana está vinculada a la filosofía antigua en lo referente a su búsqueda, defensa y fundamentación del derecho natural. Sin embargo, comparte con los modernos su preocupación por encontrar un espacio de soberanía al derecho positivo y humano. El lógos permite conocer el derecho natural mediante el entendimiento, pero también tiene la capacidad de dotar de elementos a los pactos públicos erigidos como derecho positivo. Esta tensión se resuelve en Vitoria mediante un argumento general que indica que, el derecho positivo, para considerarse válido, necesitaría no estar en contradicción con el derecho natural.

Vitoria pensó que el derecho natural puede ser conocido por todos. Consideró que dicho derecho se manifestaba en una cierta firmeza innata en el ser humano. Basándose en los principios del Digesto, aseguró que ese derecho lo ha enseñado la naturaleza a todos los animales. Siguiendo también las palabras de Pablo de Tarso sostuvo que el derecho natural está impreso en el corazón de todos los hombres: fieles e infieles. Sostuvo, pues, una idea universalista del derecho natural en la que todos los seres humanos eran reconocidos como esencialmente iguales.

31 Ibid., q. 57, a. 2, 1. 
En la filosofía vitoriana, la sociabilidad es considerada una inclinación natural que el hombre comparte con otros animales, mientras el lógos sería lo que lo hace diferente, consciente de sí, de su indigencia y de sus deberes. Gracias al lógos, el ser humano sería capaz de adiestrarse en el autocontrol y, por lo tanto, de civilizarse respetando los deberes naturales de los demás.

\section{Racionalidad y libertad}

Vitoria se inspiró fundamentalmente en la tradición aristotélica enla formulación de su concepción de la naturaleza humana. Sin embargo, su autenticidad consistió en defender una noción en la que la racionalidad no es vista como la realización de una facultad, sino más bien como la posibilidad de desarrollar una facultad. Aseguró, por lo mismo, que la facultad de raciocinio y la capacidad de deliberación es lo que hace al ser humano libre, es decir, lo que permitiría al ser humano elegir sobre su propio obrar y destino. Para Vitoria, el hombre es libre por la racionalidad, aun así, no es libre de elegir su libertad o su facultad racional, pues están impresas en la naturaleza humana Como imago Dei.

En su pensamiento, el lugar de encuentro de la racionalidad y la libertad sería la ley, pues su existencia afirmaba la existencia universal de la racionalidad y la libertad humana. Basándose en la idea de que el uso de la razón y la existencia de la libertad son el fundamento de la imputabilidad de los actos jurídicos, la filosofía vitoriana planteó que los deberes y los derechos eran solamente dos caras de la misma moneda. Si la ley positiva o humana pretendiera controlar la actividad de animales carentes de la facultad de raciocinio sería estéril e inútil, pues pretendería ordenar mediante el lógos a seres incapacitados para su comprensión. En el caso de los animales no existe, propiamente hablando, elección racional porque carecen de la facultad deliberativa y porque actúan excitados ciega y automáticamente por los instintos. Mientras tanto, en el ser humano la ley tiene un peso importante en el control de los impulsos y las pasiones, porque las normas pueden condicionar el comportamiento humano. En los animales los instintos, o las pulsiones orgánicas, se activan automáticamente. En cambio, en los animales racionales, existe una especie de momento deliberativo que permite reprimir el impulso biológico. En tal cauce, Vitoria explicó:

La ley es algo que pertenece a la razón porque mandar pertenece a la razón; y la ley es regla y medida de los actos; y recibe su nombre de ligar porque obliga. Es claro que la ley está en la naturaleza racional y 
no puede encontrarse si no es en el sentido o en el entendimiento; ahora bien, no está en el sentido; luego está en el entendimiento ${ }^{32}$.

Para Vitoria, la ley obliga a los seres humanos porque regula la actividad de agentes libres. Si los seres humanos dependieran absolutamente de sus pasiones e instintos, serían incapaces de establecer reglas generales para condicionar sus acciones. La facultad de raciocinio y entendimiento, sin embargo, permiten al ser humano el disfrute de la elección. Es esa posibilidad, y nada más que esa posibilidad, lo que permite la imputabilidad de los actos, siendo también el fundamento del reconocimiento universal de los derechos naturales en todas las personas humanas.

En De homicidio, Vitoria desarrolló gran parte de los elementos que componen su concepción antropológica, basándose en la diferencia especifica que distingue al ser humano del resto de los animales. Por un lado, indicaba que el ser humano está compuesto de dos naturalezas diferentes y disimiles, pero inseparables: la parte racional y la parte sensitiva. Inspirándose en la metáfora de Pablo de Tarso acerca del hombre exterior y el hombre interior, desarrolló una concepción en la que cuerpo y alma se unifican. En su visión, no se debe entender al alma como el hombre interior y al cuerpo como el hombre exterior. Opuestamente, plantea que "todo el hombre, según el espíritu, es el hombre interior, y según la carne, es el hombre exterior y la naturaleza sensitiva" ${ }^{33}$. Ahí mismo advirtió también que lo que constituye la excelencia o diferencia específica del ser humano es su parte interior: su racionalidad. Señaló, asimismo, que la inclinación particular del ser humano se encuentra en actuar según la voluntad y el entendimiento, y no según la parte sensitiva como lo hacen los animales. Dedujo, de estas ideas, que los actos humanos provienen del libre arbitrio, es decir, surgen de la función intelectual del entendimiento y de la función volitiva de la deliberación. Por lo mismo, argumentó que "los movimientos del apetito que preceden a la voluntad no se llaman actos humanos" 34 .

Vitoria planteó también la existencia de una contradicción interna en la naturaleza humana. Por un lado, estaría la inclinación racional del hombre que proviene del entendimiento y de la voluntad libre. Por otra, la inclinación sensitiva del hombre que proviene de los impulsos y las pasiones. Solamente los principios que derivan de la inteligencia y de la voluntad libre o deliberación serán reconocidos como humanos,

32 Ibid., q. 90, lectura 121, a. 1.

${ }^{3}$ FRANCISCO DE VITORIA, "De homicidio", in: FRANCISCO DE VITORIA, Relecciones teológicas, p. 1096.

34 Ibid., p. 1097. 
considerando al resto como inclinaciones que compartimos con todos los seres vivos.

La filosofía política de Francisco de Vitoria puede considerarse expresada como una visión optimista de la naturaleza humana, en la que que el desarrollo de la libertad y la racionalidad es la única vía posible para formar sociedades justas. En sus propias palabras "no sería racional que Dios negase al hombre la inclinación a su fin propio habiéndosela concedido a los seres inanimados o a los miembros del cuerpo" 35 .

En la concepción antropológica de Vitoria es latente la idea de que el ser humano está facultado con la capacidad intelectual del entendimiento y con la capacidad volitiva de la deliberación para desarrollar el libre arbitrio. Su reflexión, en este sentido, parece universalmente aceptable. $\mathrm{Si}$ al hombre se le puede hacer responsable de sus actos, si se puede vincular su obrar con su intención, es porque se cree que la facultad racional tiene la capacidad de actuar como causa (motivo) y medida del obrar. En caso contrario, si el ser humano estuviera esclavizado a sus instintos e impulsos, sin poderlos reprimir o suspender, no sería libre, porque esas fuerzas interiores le determinarían infaliblemente. El hogar de la libertad es, pues, la racionalidad, entendiéndola como una facultad que hace posible el entendimiento y la voluntad, es decir, el obrar teniendo en consideración móviles de diferente naturaleza a las pasiones o afecciones.

En De aumento caritatis, de 1535, Vitoria planteó las características de la libertad del obrar humano, no sólo respecto a las pasiones o impulsos naturales, sino también respecto a la fuerza externa que constituye Dios. Para los protestantes como Lutero, la libertad humana está totalmente determinada, pero no solamente por las inclinaciones animales y el pecado original, sino por la predestinación. Esto significaría que la voluntad humana no podría ser libre porque lo único realmente libre sería la voluntad de Dios. Frente al concepto pesimista de la naturaleza humana: "El humanismo vitoriano, que posee seguras bases tomistas, surge de una concepción positiva del hombre: el pecado no habría destruido en la persona humana, ni siquiera en los niños, la imagen de Dios"36.

Para Vitoria, tener uso de razón se corresponde con la capacidad de emplear el entendimiento y la voluntad. Consideró, en suma, a la racionalidad como una facultad de la que ningún ser humano está privado enteramente. Adelantándose a nuestra época, llegó a sostener

\footnotetext{
35 Ibid., p. 1104.

36 SORIA, C. I diritti dell'uomo e la pace nel pensiero di Francisco de Vitoria e Bartolomé de las Casas, p. 289.
} 
derechos especiales para personas con discapacidades mentales y para los niños.

Las dos condiciones de posibilidad de la libertad, como facultad derivada del raciocinio, serían las siguientes:

1. Que el hombre tenga facultad para discurrir y deliberar qué es bueno y qué es malo, qué debe conseguir y qué ha de huir y evitar.

2. Que una vez que haya deliberado, tenga poder para tomar o dejar lo que haya deliberado ${ }^{37}$.

Las ideas de libertad y racionalidad, en Vitoria, están estrechamente vinculadas, pudiéndose considerar inseparables. La noción de racionalidad tiene claras influencias del pensamiento aristotélico, pues la primera condición de posibilidad de la libertad es el lógos. Gracias a esta capacidad, el ser humano es capaz de deliberar y especular acerca de lo justo y lo injusto, lo provechoso y lo nocivo, lo bueno y lo malo. Pero la libertad no debe ser entendida como una capacidad irreversible. Opuestamente, lo que hace al ser humano libre es su capacidad de elección, pero también su capacidad de corrección por medio de la reflexión y el aprendizaje empírico. Sin el entendimiento y sin la deliberación, lo único que habría en el ser humano serían los impulsos, los instintos, las pasiones y las afecciones del cuerpo.

Cuando Vitoria se pregunta por qué razón, siendo todos los hombres de la misma especie y poseyendo las mismas capacidades racionales, en algunos puede no encontrarse el uso de la razón, responde que ese defecto proviene de la parte sensitiva ${ }^{38}$. Con ello se refiere a los sentidos y a las afecciones. Consideraba que las perturbaciones y las pasiones pueden impedir el uso de la razón, porque contaminan los juicios deliberativos, así como la intelección especulativa. Por lo mismo, pensaba que cuando los seres humanos actúan por ira o por los apetitos carnales, esas pasiones producen frenesí y locura ${ }^{39}$. Ese tipo de acciones, que recuerdan mucho el estado de las sociedades en las guerras representarían el lado opuesto a la civilidad, es decir, la violencia y la barbarie, un estado social sin derechos y sin obligaciones.

En la filosofía vitoriana, la racionalidad y la libertad son dos facultades estrechamente relacionadas. Ningún ser humano estaría privado por entero de ellas, puesto que constituyen los elementos fundamentales de la naturaleza humana. Mientras la racionalidad sirve para que el ser humano pueda desarrollar su propia naturaleza, la libertad se favorece de la deliberación y del entendimiento para entablar

37 FRANCISCO DE VITORIA, "De aumento caritatis", in: FRANCISCO DE VITORIA, Relecciones teológicas, p. 1315.

38 Ibid., p. 1318.

39 Ibid., p. 1320. 
una relación creativa que permite la salida de su condición indigente, vulnerable y deficitaria.

\section{Conclusiones}

A lo largo del presente artículo, hemos revisado las nociones de naturaleza y condición humana, así como el origen de la sociedad civil y el poder político, en la filosofía vitoriana. Hemos podido advertir que la concepción particular de Vitoria respecto al tema de la gracia divina le permitió distinguir el mundo secular del eclesiástico. Igualmente, dicha distinción le permitió desmarcarse de las filosofías que consideraban determinante el estado de gracia respecto al origen del derecho a la autoridad y del derecho a la propiedad. En su filosofía, la naturaleza humana no se encuentra corrompida radicalmente por el pecado original o por la infidelidad. Esta concepción antropológica de carácter positivo es el fundamento de su filosofía política, la que se caracteriza por un inusitado humanitarismo en la defensa de los derechos naturales de los indígenas americanos.

En su teoría sobre el origen de la sociedad civil y sobre el fundamento de la autoridad política se encuentra representado el modelo aristotélico de las cuatro causas, si bien es cierto, a partir de una interpretación sui generis. La causa eficiente de ambas las refiere a Dios. La causa final la cimienta en la utilidad, o bien, en la salida del estado de indigencia natural. La causa formal, o concepto, la concibe como la facultad de gobernar la república civil. Su gran innovación, respecto a las teorías medievales, consistió en colocar la causa material en la propia república, inaugurando una tradición según la cual la legitimidad del poder recae directamente en los miembros de la sociedad. A la par, su visión puede considerarse como una de las primeras filosofías medievales en las que se defendió una visión universalista de los derechos humanos, en tanto que afirmó la presencia de dichos derechos en los indígenas americanos.

Las teorías de Vitoria serían incomprensibles sin su contexto. Por una parte, sus tesis tienen una fuerte carga teológica. Por otra, Vitoria siempre busco remitir sus nociones filosóficas al análisis de fuentes seculares como el aristotelismo, si bien es cierto, intentando corregirlas mediante los preceptos de la caridad cristiana. La filosofía vitoriana representa, pues, un punto de inflexión histórica en la que comenzó a aceptarse la idea de que la forma adoptada por el poder civil recae en los miembros de la república, así como la idea de proteger los derechos humanos. Su particular concepción de la condición humana (como un estado de vulnerabilidad y de indefensión biológica), así como su concepción de la naturaleza humana (la reunión de distintas facultades 
como el lógos, la racionalidad, la libertad y la sociabilidad en las personas humanas) permiten considerar sus ideas como un pequeño paso hacia las concepciones filosóficas modernas. De hecho, es bastante probable que la ventaja de las tesis vitorianas, respecto a otras más actuales, consista en su compromiso absoluto con la defensa de una concepción incluyente de los derechos humanos, la cual parte del reconocimiento universal del lógos en todas las personas humanas, independientemente de sus creencias religiosas o políticas.

\section{Referencias}

ARISTÓTELES. Metafísica. Edición trilingüe de Valentín García Yerba. Madrid: Gredos, 2012.

CRUZ, Juan. Ley y dominio en Francisco de Vitoria. Pamplona: Eunsa, 2006.

. Fragilidad humana y ley natural. Cuestiones disputadas en el siglo de Oro. Pamplona: Eunsa, 2009.

DÍAZ, Bárbara. El internacionalismo de Vitoria en la era de la globalización. Pamplona: Universidad de Navarra, 2005.

FOUCAULT, Michel. Sicurezza, territorio, popolazione. Corso al Collège de France (1977-1978). Milano: Feltrinelli, 2005.

FRANCISCO DE VITORIA. Comentarios a la II-II. Edición en latín de Vicente Beltrán de Heredia. Salamanca, 1932.

. Relecciones teológicas. Edición crítica del texto latino y versión española por Teófilo Urdánoz. Madrid: Biblioteca de Autores Cristianos, 1969.

GÓMEZ, Antonio. Política de Vitoria. México: Universidad Nacional, 1940.

ORREGO SÁNCHEZ, Santiago. La actualidad del ser en la primera escuela de Salamanca. Con lecciones inéditas de Vitoria, Soto y Cano. Pamplona: Eunsa, 2004.

PÉREZ, Antonio. La polémica sobre el Nuevo Mundo. Los clásicos españoles de la Filosofía del Derecho. Madrid: Trotta, 1992.

PÉREZ, Diego. El problema de la fundamentación filosófica de los derechos humanos y las contribuciones de Francisco de Vitoria. Madrid: Universidad Complutense de Madrid, 2011.

REDMOND, Walter. El albedrío. Proyección del tema de la libertad desde el Siglo de Oro Español. Pamplona: Cuadernos de Pensamiento Español, 2007.

RODRÍGUEZ, Marcelino. La doctrina colonial de Francisco de Vitoria o el derecho de la paz y la guerra. Un legado perenne de la Escuela de Salamanca. Salamanca: Cervantes, 1993.

SÁNCHEZ, Isabe. La eclesiología de Francisco de Vitoria. Pamplona: Universidad de Navarra, 1978.

SCHAETZEL, Walter. La teoría de la guerra de Francisco de Vitoria y la moderna guerra de agresión. Traducción de Antonio Truyol y Serra. Murcia: Universidad de Murcia, 1954. 
D. A. P. Rivas - Condición, naturaleza humana y el origen ...

SORIA, Carlos et al. Convegno: I diritti dell' uomo e la pace nel pensiero di Francisco de Vitoria e Bartolomé de las Casas. Roma: Università S. Tommaso (Angelicum), 1985.

STEGMÜLLER, Federico. Francisco de Vitoria y la doctrina de la gracia en la Escuela Salmantina. Barcelona: Balmes, 1934.

TILESI, Silvano. La guerra in Francisco de Vitoria. Roma: Pontifica Universitas Lateranensis, 1973.

TITOS LOMAS, Francisco. La filosofía política y jurídica de Francisco de Vitoria. Córdoba: Publicaciones del Monte de Piedad y Cajas de Ahorros de Córdoba, 1993.

TOMÁS DE AQUINO. Suma teológica II. Traducción por comisión dominica presidida por Francisco Barbado Viejo. Madrid: Biblioteca de Autores Cristianos, 2010.

TRUYOL, Antonio. Los principios del derecho público en Francisco de Vitoria. Madrid: Ediciones de Cultura Hispanica, 1946.

\section{Endereço postal:}

Diego Alfredo Pérez Rivas

Corso Dante, 12

Moncalieri (TO)

Italia, CAP 10024

Recebimento: 12/03/2014

Aceite: 30/05/2014 